\title{
Somos todos trabalhadores em Educação? Reflexões sobre identidades docentes desde a perspectiva de sindicalistas ${ }^{*}$
}

\author{
Márcia Ondina Vieira Ferreira
}

Universidade Federal de Pelotas

\author{
Correspondência: \\ Márcia Ondina Vieira Ferreira \\ Faculdade de Educação - UFPel \\ Rua 15 de Novembro, 155 \\ 96015-000 - Pelotas - RS \\ marciaof@ufpel.edu.br
}

\section{Resumo}

0 trabalho discute implicações do fenômeno da sindicalização docente sobre as identidades da categoria, em especial ao considerar-se o alegado processo de proletarização e a inclusão de funcionários nas entidades sindicais docentes. Baseia seus argumentos em duas pesquisas realizadas com sindicalistas do CPERS/ SINDICATO (Centro dos Professores do Estado do Rio Grande do Sul - Sindicato dos Trabalhadores em Educação), que apresentam diferentes graus de participação na hierarquia política da organização. 0 referencial teórico recupera a gênese da escola e da docência, abordando duas de suas mais significativas imagens: trabalho feminino e proletarizado. Discorre sobre a sindicalização docente no Brasil, fenômeno que se oficializa a partir da promulgação da Constituição de 1988, mas que se consolida anteriormente a isso: durante as lutas por liberdades democráticas no contexto ditatorial. A análise revela uma variedade de posições, entre os sindicalistas, sobre a identidade dos docentes com relação à sua condição de trabalhadores em Educação ou de profissionais, ainda que um traço unificador seja a ausência de menção às modificações no processo de trabalho docente para justificar a proletarização. Também há concordância quanto ao aspecto instrumental das filiações, isto é, que a maior parte das pessoas se filia para obter vantagens pessoais. Nas conclusões, aponta-se para o caráter híbrido das atuais identidades docentes. Também se propõe para análise o fato de que, embora o termo 'trabalhadores em Educação' pudesse indicar uma diluição do professorado nos demais segmentos que atuam na escola, é perceptível o oposto, sendo os funcionários subsumidos na categoria docente.

\section{Palavras-chave}

Trabalho docente - Sindicalismo docente - Identidade docente Trabalhadores em Educação. 


\title{
Are we all workers in Education? Reflections about teacher identities from the teachers' Union perspective*
}

\author{
Márcia Ondina Vieira Ferreira \\ Universidade Federal de Pelotas
}

\author{
Contact: \\ Márcia Ondina Vieira Ferreira \\ Faculdade de Educação - UFPel \\ Rua 15 de Novembro, 155 \\ 96015-000 - Pelotas - RS \\ marciaof@ufpel.edu.br
}

"This is an expanded version of a work presented at the $12^{\text {th }}$ National Meeting of Didactics and Teacher Practice, held at PUCPR, Curitiba, in 2004. The studies that have given support to this text were supported by CNPq, FAPERGS and UFPel. I thank CPERS/ SINDICATO, the people interviewed, and the members of my research teams (Adélia Porto de Souza, Ana Helena Beckenkamp, Jenice Tasqueto de Mello, Josiane Bacelo, Lencioni Fischer, Marcele Volcan de Matos, Raquel Perpétua Paré da Costa).

\begin{abstract}
The work discusses implications of the phenomenon of teacher Union affiliation upon the identities of this category, especially when considering the alleged process of its proletarianization, and the inclusion of other school personnel in the teachers Unions. The arguments are based on two studies carried out with Union officials from CPERS/SINDICATO (Teachers Center of the State of Rio Grande do Sul - Union of Workers in Education), representing different degrees of participation in the political hierarchy of the organization. The theoretical framework used recovers the genesis of school and teaching, approaching two of its most significant images: women's work and proletarian work. The article speaks of the affiliation of teachers to Unions in Brazil, a phenomenon that becomes official after the promulgation of the 1988 Constitution, but that had consolidated before that: during the struggles for democracy under the dictatorship. The analysis reveals a variety of positions among Union officials with regard to the teachers' identities as workers in Education or as professionals, even though a universal feature is the absence of mentions to the modifications in the process of teacher work to justify the proletarianization. There is also agreement with respect to the instrumental aspect of the affiliations, that is, to the fact that most people become affiliated to obtain personal advantages. The conclusions point out to the hybrid character of the current teachers' identities. They also present for analysis the fact that, although the phrase "workers in Education" might indicate a dilution of teachers among the other categories of workers of the school, the opposite is noticeable: the teacher category subsumes the other school personnel.
\end{abstract}

\section{Keywords}

Teacher work - Teacher Union movement - Teacher identity Workers in Education. 


\section{Foco do trabalho e definições básicas}

Esse artigo pretende colaborar com os debates sobre o tema do trabalho docente, partindo de dois enfoques articulados: a dicotomia entre processo de proletarização e reivindicação de profissionalidade; e a sindicalização como indicador de uma das identidades da categoria. Quanto ao primeiro aspecto, desde as últimas décadas do século $X X$, vimos assistindo a modificações substanciais nas formas de gestão dos sistemas educacionais, que repercutem sobre a organização e a divisão do trabalho docente. Para muitos analistas, deparamo-nos com um fenômeno de proletarização, que apresenta relações com a perda de status social e a pauperização da categoria. Ao mesmo tempo, quanto mais se amplia o sistema de ensino e mais se 'proletariza' a categoria, mais se reivindica a profissionalidade da atividade realizada, num intento de refrear o processo e reconquistar o status perdido.

Já a sindicalização do professorado faz parte dessa situação contraditória: a organização aos moldes dos trabalhadores manuais (proletarizados) expressaria a forma encontrada para resistir às perdas sofridas.

Do ponto de vista metodológico, para estudar essas temáticas, não venho me ocupando da análise do processo de trabalho docente propriamente dito, mas do exame dos argumentos utilizados pelo professorado para explicar sua situação, que podem reverter no tópico relativo aos motivos da sindicalização docente. Esse procedimento metodológico advém de uma opção por conhecer como as pessoas constroem suas identidades e quais representações a respeito do trabalho docente circulam nos âmbitos escolares. Compartilho, também, da idéia de que tanto as representações, quanto as identidades, não são fixas e sim produzidas e reproduzidas cotidianamente, não sendo inerentes aos indivíduos.

Neste texto, pretendo abordar aspectos do processo de sindicalização do professorado, tendo por base dados coletados em duas pes- quisas, realizadas a partir de 1999 , focalizadas no CPERS/SINDICATO (Centro dos Professores do Estado do Rio Grande do Sul - Sindicato dos Trabalhadores em Educação), o maior sindicato de trabalhadores em Educação do Rio Grande do Sul.

Para efeitos da análise que apresentarei, reuni informações obtidas a partir de três grupos de sujeitos que atuam no referido sindicato, separados por seu grau de participação na hierarquia política da entidade. 0 primeiro grupo foi composto por oito dirigentes docentes do CPERS/SINDICATO em nível estadual - cinco mulheres e três homens -, que participaram de, pelo menos, uma das diretorias da década de 1990, isto é, gestões 90/93, 93/96 e 96/99. Nesse grupo, todos são filiados a partidos políticos, de espectros diferenciados, bem como pertencem a correntes sindicais diferenciadas.

0 segundo grupo reúne 17 docentes (13 mulheres e 4 homens) pertencentes ao Conselho de Representantes de uma seção regional do Sindicato, o 24 Núcleo (gestão 1999/2002). Nesse grupo, formado principalmente por representantes da base do sindicato, isto é, representantes por escola, a filiação a partidos e a participação em correntes sindicais são variadas, havendo muitos membros que são politicamente independentes, ou seja, não possuem identificação partidária e/ou sindical precisa.

Ao terceiro grupo, pertencem cinco mulheres e dois homens da diretoria do mesmo $24^{\circ}$ Núcleo (gestão 2002/2005), sendo que uma das mulheres é servidora (funcionária) e os demais, docentes. Esses sujeitos pertencem à mesma corrente sindical e nem todos são filiados a partidos, embora sejam simpatizantes.

Com o primeiro e o terceiro grupos, foram utilizadas entrevistas semi-estruturadas e, com o segundo, foi aplicado um questionário com questões abertas.

Tendo por base os achados obtidos junto com todos esses sujeitos, quero discorrer sobre as seguintes questões: que motivos são apresentados para a sindicalização de docentes? Que argumentos são desenvolvidos para 
considerarem-se os docentes profissionais ou proletários? Apresenta conseqüências, para as identidades docentes, o fato de o sindicato ter incorporado outros segmentos que atuam na área educacional, passando a intitular-se um sindicato de trabalhadores em Educação?

Nas próximas duas seções, visando definir o arcabouço teórico utilizado para interpretar os dados, algumas referências serão apresentadas. Em seguida, serão elencadas informações sobre o sindicato estudado para, logo depois, discutir os dados propriamente ditos. Fechando o artigo, encontramos as idéias conclusivas.

\section{Gênese da escola moderna e da docência}

Tal como a escola que conhecemos hoje no ocidente, as características da docência foram sendo estabelecidas gradativamente, modificando, ora de forma suave ora radicalmente, as imagens representativas de quem dela se ocupou no transcorrer dos séculos.

0 processo de desenvolvimento da escola dita moderna foi longo, estendendo-se da ldade Média à Moderna. Podemos até dizer que ele contribuiu para a produção da ldade Moderna, incluindo transformações na idéia de infância; do que seria educação; e de onde a educação (das crianças) deveria ocorrer. Diversos autores convergem à idéia de que, paulatinamente, a concentração urbana, a ascensão da burguesia como classe dominante, a disseminação do liberalismo econômico e dos ideais da llustração, entre outros fatores, edificaram a perspectiva de uma escola afastada de seu berço: a Igreja (Clausse, 1977; Lerena, 1985; Petitat, 1989).

No entanto, segundo Nóvoa (1991), o processo de estatização da escola começa, efetivamente, nos finais do século XVIII, trazendo também transformações na concepção de docente. Ao Estado laico, atribui-se o dever de ensinar e escolarizar, apresentando a necessidade da 'funcionarização' da docência. Ainda assim, "como a gênese da profissão docente é anterior à estatização da escola” (p. 118), a constituição desse profissional está marcada pela idéia da docência como sacerdócio, e isso convive com as características que começam a ser associadas ao ofício. Dentre estas, é possível citar a permissão ou licença para ensinar, que estabelece certa autonomia profissional.

Contudo, essa autonomia é apenas parcial: como funcionários do Estado, o professorado tem que se submeter a um controle ideológico e político, ainda que não renuncie a reivindicar "um regulamento menos administrativo (no sentido burocrático) e mais profissional (no sentido liberal)" (Nóvoa, 1991, p. 123).

Cabe enfatizar, aqui, essa ânsia por aproximar-se das profissões liberais, que é examinada por Fernández Enguita (1991) ao discutir a idéia de docência como semiprofissão. Competência, vocação, auto-regulação, licença e independência são características das profissões liberais que só de forma parcial ocupações, como a docência, compartilham. Embora necessitem de uma formação/titulação específica, a competência dos docentes freqüentemente é questionada quanto mais nos aproximamos da atualidade. Vocação, para os docentes, tem sido entendida como renúncia a condições de trabalho e de vida compatíveis, a priori, com sua titulação, o que resta àqueles que não conseguiram encontrar coisa melhor. 0 ingresso na profissão e o controle de seu exercício, conhecidos como auto-regulação, são atribuições do empregador, isto é, do Estado, carecendo o professorado de um código de ética particular. Quanto à licença para ensinar, se bem que só quem seja considerado docente possa lecionar, hoje existem possibilidades de ensinar em cursos não regulados e/ou em áreas de conhecimento ou níveis de ensino em que não existe formação específica para a docência (como é o caso do ensino superior). Por fim, quanto à independência, o grau de autonomia do professorado é relativo tanto quanto às organizações (Estado e outros empregadores), como quanto ao seu público (comunidade escolar). 
De todas as formas, no intuito de fortalecer a docência como profissão, o professorado passa a reivindicar uma formação específica, o que só se concretizará mais organizadamente a partir do século XIX. Nóvoa (1991) assinala que a criação de escolas de formação de docentes, resultado das pressões dos mesmos, vem a inaugurar um sistema de "estratificação social baseada em critérios escolares e no princípio da superioridade daqueles que dão a instrução" (p. 125).

Em outras palavras, os docentes buscam acrescentar, ao estado incorporado do capital cultural que detém, um estado institucionalizado desse capital, representado pela credencial educativa impressa no diploma (Bourdieu, 1999). Com isso, que tipo de pessoal passa a ser recrutado para trabalhar como docente? "Os mestres miseráveis e pouco instruídos do início do século XIX vão, em algumas décadas, ceder lugar a profissionais formados e preparados para o exercício da atividade docente" (Nóvoa, 1991, p. 125). Porém, a partir dos anos 50 do mesmo século, uma série de modificações ocorridas nos países ocidentais vai, paulatinamente, influenciar no recrutamento desses 'profissionais', desembocando na feminização da docência.

Por feminização, compreende-se o resultado de um processo de ampliação massiva da força de trabalho feminina na docência (feminilização), que paulatinamente operou sobre as representações quanto ao caráter desse trabalho, incluindo seu valor social (Yannoulas, 1996). No momento presente, feminização e proletarização são as características mais evidentes da docência e, segundo alguns autores - como Apple (1987) -, interconectadas. Para ele, no transcorrer de décadas, formas patriarcais de controle sobre o ensino foram sendo substituídas por formas mais técnicas, associando esse fenômeno à proletarização vivida pelo professorado, principalmente a partir da segunda metade do século passado. De todas as maneiras, durante todo esse tempo, coabitaram várias representações sobre a docência, sendo que em todas elas os gêneros tiveram papel importante, em especial no que tange ao gêne- ro feminino, de tal modo que o magistério passou a ser reconhecido como um trabalho de mulher (Louro, 2001).

Assim, como desde o ponto de vista sociológico quanto maior tem sido o grau de feminização, maior também o grau de proletarização de uma categoria, esses dois fenômenos foram sendo associados, declarando ou decretando a menor necessidade da mulher professora a um melhor salário e um maior status profissional. Contudo, cabe assinalar que, com o desprestígio e a pauperização, o professorado organizou-se, especialmente a partir do passado século, em entidades sindicais que, por sua natureza - melhor dizendo, por sua construção histórica e cultural - subsumiram os sujeitos generificados numa idéia de classe social desgenerificada. É perceptível, nos sindicatos docentes, a escassez de discussão sobre as relações de gênero na sociedade e na educação, tal como em outros sindicatos ou qualquer esfera de atuação pública da humanidade e, inclusive, em grande parte da literatura acadêmica que interpreta os fenômenos sociais (Ferreira, 2004).

Por fim, chama a atenção o aspecto contraditório que apresenta a sindicalização do professorado, em termos de identidade ocupacional. Conforme alguns autores (Arroyo, 2002; Tiramonti, 2001), são híbridas as identidades docentes em relação a ser trabalhador/a ou profissional. Os motivos para a sindicalização não ocorrem necessariamente porque alguém se identifique com a primeira categoria, mas por motivos de ordem instrumental, ou seja, para obter vantagens individuais mais imediatas. Isso é o que veremos a seguir.

\section{Por que o professorado se sindicaliza?}

0 fenômeno da sindicalização de docentes é internacional, ainda que com particularidades conforme o país e, também, o continente. No Brasil, essa sindicalização radicaliza-se durante a transição democrática, principalmente porque, sendo a maioria do professorado com- 
posta pelo funcionalismo público, este esteve impedido de criar sindicatos até o término da ditadura e a promulgação da nova Constituição em 1988. Anteriormente havia associações (não sindicais) de docentes, que "surgiram junto com a organização das redes de ensino público, a partir dos anos 30" (Souza, 1997, p. 145).

Contudo, muitas dessas associações, durante as lutas por liberdades democráticas, embora não pudessem se instituir oficialmente como sindicatos, atuavam como tal, tanto no âmbito da redemocratização da sociedade quanto no das reivindicações corporativas.

Características, então, do sindicalismo docente brasileiro, em especial do professorado público, mesmo antes de adquirir direito à greve, são as mobilizações massivas, típicas do sindicalismo combativo; a organização pela base, isto é, por local de trabalho (escola) e região, representando-se finalmente em organizações regionais; a paulatina identificação com o 'novo sindicalismo', por meio da filiação das entidades à CUT (Central Única dos Trabalhadores); e a posterior unificação de docentes e do funcionalismo em entidades únicas, no caso do ensino básico. Atualmente, após a Constituição, a entidade que congrega nacionalmente as demais entidades regionalizadas é a CNTE (Confederação Nacional dos Trabalhadores em Educação), originada da CPPB (Confederação dos Professores Primários do Brasil). Em suma, pode-se afirmar que as atuais entidades docentes possuem formas de organização e de atuação que as tornam semelhantes a entidades não profissionais. Além disso, tal formato organizativo poderia indicar um dos tipos de identidade ocupacional e/ou ideológica que o professorado vem assumindo.

Desse modo, referindo-se à CNTE, Gadotti busca explicar as mudanças na consciência do professorado em relação à sua posição social:

A denominação 'trabalhadores em educação', em vez de 'educadores', 'professores' ou 'profissionais da educação', reflete a mudança de per- cepção da própria categoria no conjunto dos trabalhadores em geral. Ela toma consciência de que os problemas que afetam os docentes são basicamente os mesmos de outras categorias de trabalhadores. Portanto, as lutas do magistério são consideradas, a partir de então, semelhantes às dos trabalhadores em geral. (1996, p. 15)

Em sentido semelhante, vale a pena resgatar a posição de Arroyo na época das lutas por liberdades democráticas, expressa em evento realizado em 1979, em texto com sugestivo título, publicado em periódico com capa igualmente sugestiva. Trata-se do artigo "Operários e educadores se identificam: que rumos tomará a educação brasileira?", que encabeça a revista em cuja capa destaca-se a associação EDUCADOR = TRABALHADOR. Nesse texto, o autor pretendeu sistematizar algumas posições, encontradas na prática mobilizatória dos docentes e na pesquisa educacional, a respeito da nova identidade docente. Por isso, defendia que esta revelaria o tipo de articulação entre a categoria dos docentes e os demais trabalhadores, necessária para "lutar contra a escola burguesa" (1980, p. 16):

A nova consciência e nova prática dos trabalhadores da educação é se sentirem como trabalhadores e sentirem a necessidade de se associarem como tais, e organizarem sua luta nos mesmos moldes dos trabalhadores da produção, do comércio [...] e sobretudo se sentirem solidários nos mesmos objetivos de questionar 0 modelo sócio-político e econômico, o Estado, a organização do trabalho [...] que os gera e explora como trabalhadores. (1980, p. 17-18)

De fato, naquela ocasião, Arroyo apresentava as modificações no processo de trabalho docente como semelhantes às vivenciadas pelos trabalhadores em geral, indicando, portanto, a pertinência do 'ingresso' do professorado nas fileiras do movimento operário:

0 fato de ser uma luta da última categoria (dos docentes), mostra que os efeitos da política 
educacional que implantou no sistema escolar a organização do trabalho que domina a produção empresarial capitalista está gerando suas contradições. Se o que se pretendia era a divisão e a hierarquização do trabalho educativo, o que se gerou foi a parcelação, diferenciação salarial e funcional, a depreciação do trabalho dos educadores de base, a grande massa e, conseqüentemente, se gerou sua consciência e organização. (1980, p. 17)

Numa abordagem que incide mais sobre a atuação concreta do movimento sindical docente, desde as lutas sociais pelo término do regime de excessão, Souza (1997) indica quatro momentos significativos. 0 primeiro seria o da redemocratização, que conduziria a uma nova ordem jurídico-institucional. 0 segundo, o da promulgação da Constituição, na qual o movimento sindical esperava ver gravadas a ampliação do direito à educação e a melhoria das condições de trabalho. 0 terceiro momento ocorreu em 1989, com a primeira eleição direta para presidente depois do término da ditadura, no qual se esperava a discussão de projetos educacionais para o país. E o último momento refere-se à resistência às políticas de reajuste trazidas pelo cenário neoliberal. Como resultado desse processo, a autora assinala que o movimento docente tem mais apresentado estratégias defensivas de seus direitos do que elaborado estratégias propositivas.

Por outra parte, o que se depreende dessas décadas de atuação político-sindical do professorado, agora agrupado com outros funcionários educacionais sobre a égide de 'trabalhadores em Educação', é que a opção pela sindicalização, como opção por uma identidade de classe, parece ser uma das imagens majoritárias da docência na atualidade. 0 movimento sindical docente atua segundo o que se espera de um movimento de trabalhadores assalariados, ligado à CUT e possuindo grande parte de seus ativistas identificados com o PT (Partido dos Trabalhadores) ou outros grupos no espectro político de esquerda, sendo que a maior parte das discussões e reivindicações apresentadas se situa no âmbito econômico, principalmente defesa salarial e melhoria da carreira. Guardando-se as diferenças regionais, o grau de filiação às entidades é alto, embora esse indicador tenha que ser relativizado, segundo Cardoso,

[...] a filiação não pode ser tomada como medida universal da legitimidade vertical da representação do sindicalismo, seja porque parte dos não-filiados também participa da ação coletiva, seja porque muitos filiados não participam. (1999, p. 96-97)

Porém, essa identidade começaria a apresentar fraturas. Souza (1997), já citada, afirma que "as representações que os professores elaboram sobre o sindicato evidenciam uma contradição entre lutas educacionais e lutas sindicais" (p. 157), - de tal maneira que esses passam a encará-lo "como uma entidade desencadeadora de greves" (p. 151) -, o que, por sua vez, desemboca em insatisfação por parte dos usuários da escola. Também Vianna, em revisão sobre o assunto, apresenta indicadores

[...] da crise da organização sindical docente: 1) esgotamento das greves; 2) ausência de diálogo com a população usuária das escolas públicas; 3) divergências político-ideológicas nas entidades; 4) distância entre as lideranças das associações/sindicatos e o professorado. (1999, p. 36)

Ainda assim, não há indícios de que tal crise tenha promovido modificações substanciais, nem sobre a imagem 'proletária' da docência nem sobre o próprio processo de sindicalização dos docentes, isto é, de filiação. Como indicado, a imagem 'proletária' é uma das existentes que convive com o desejo de profissionalização, isto é, essas identidades não necessariamente são excludentes.

Abordando, agora, os motivos para a filiação ao sindicato docente, também podem ser vários, tal como nos orienta Guerrero Serón 
(1991). 0 autor indica três principais motivos: os ideológicos, os solidários e os instrumentais, que se referem, respectivamente, à defesa das crenças, dos interesses coletivos e dos interesses individuais. Parece-me que esses motivos se misturam freqüentemente, mas poderíamos concordar com a hipótese de que a maioria se sindicaliza por motivos instrumentais ou que qualquer pessoa possui esse motivo em mente quando se sindicaliza.

Tomando o caso do Brasil, e desde o ponto de vista cronológico, poderíamos pensar que quanto mais regredimos à época da luta contra a ditadura militar, mais nos aproximamos de filiações por motivos ideológicos e solidários. Já a idéia de que o sindicato é um desencadeador de greves, mais recente, indica certo desgaste das formas de lutas tradicionais e esquecimento histórico dos momentos iniciais da criação dos sindicatos, sendo muito provavelmente apresentada por quem se sindicalizou mais recentemente, por motivos instrumentais. Pessoas que são, por sua vez, 'compreendidas' por aqueles que se preocupam mais pelos interesses coletivos, e não por aqueles que militam por suas crenças, que continuam a defender que a filiação sindical ocorra por obrigatoriedade moral, por convicções políticas ou coerência. Tendo em vista esse panorama esboçado superficialmente, uma questão é o quanto o movimento docente será capaz de renovar-se para dar vazão a outras políticas identitárias, ou seja, se está preparado para perceber que novos docentes ingressam nas redes com outras histórias de vida e concepções de mundo.

\section{- CPERS/SINDICATO, seus membros e sua direção}

Nesta seção, serão oferecidas algumas informações a respeito da entidade estudada e de seus membros, visando dar uma idéia sobre suas formas de organização e sua origem.

0 CPERS/SINDICATO é a entidade representativa do professorado (ensino fundamental e médio) ligado ao Sistema Público Estadual de Ensino do Estado do Rio Grande do Sul. Esta é a atual denominação da Associação Civil "Centro dos Professores do Estado do Rio Grande do Sul", transformada em sindicato em 1989. Contudo, sua origem remonta ao "Centro dos Professores Primários Estaduais", fundado em 21 de abril de 1945. Filiado à CUT desde 26 de abril de 1996, conta com 42 núcleos regionais, organizações de base que respondem à divisão oficial das estruturas de administração educacional do estado, as Coordenadorias Regionais de Educação (CREs). Posso exemplificar explicando que o $24^{\circ}$ Núcleo, onde foi coletada parte dos dados discutidos neste trabalho, tem atuação nos mesmos municípios administrados pela $5^{\text {a }}$ CRE, ambos sediados em Pelotas.

Podem associar-se ao CPERS/SINDICATO “os professores, especialistas em educação e funcionários de escola e dos demais órgãos do Sistema Estadual de Ensino que sejam servidores públicos do Estado do Rio Grande do Sul" (CPERS/SINDICATO, 1994, p. 2), sendo que os funcionários foram incorporados em março de 1990 (Bulhões; Abreu, 1992).

Desde a reforma estatutária de 1994, as instâncias de direção do referido sindicato são a Diretoria e o Conselho Geral. A primeira possui os seguintes cargos: presidente, $1^{\circ}$ vicepresidente, $2^{\circ}$ vice-presidente, secretário-geral, tesoureiro geral e mais outros dez diretores com atribuições definidas pelo conjunto da Diretoria. 0 Conselho Geral é formado pela diretoria, diretores gerais de Núcleo, um representante para cada mil sócios do Núcleo, dois representantes estaduais dos associados aposentados e representantes de base do CPERS/SINDICATO no Conselho de Entidades da CNTE.

Por sua vez, os Núcleos possuem uma Diretoria e um Conselho do Núcleo, sendo a primeira composta por um diretor geral, um vice-diretor, um secretário, um tesoureiro e mais cinco diretores, com atribuições definidas pela Diretoria do Núcleo. Já o segundo organismo está constituído pela Diretoria do Núcleo, representantes de escolas na proporção de um por escola ou órgão do sistema estadual de ensino e mais um a cada 50 sócios, dois representantes dos aposen- 
tados do Núcleo, um representante municipal e um representante 1/1000 daquele Núcleo.

Essa forma de organização busca atender à representação a partir das bases, posto que, primeiro, embora as eleições para a Diretoria do CPERS/SINDICATO, para as Diretorias dos Núcleos e dos representantes 1/1000 sejam feitas por chapas, não há vinculação direta entre elas. Segundo, as eleições dos representantes de escola são realizadas em cada estabelecimento escolar ou local de trabalho. Isso significa que diferentes correntes políticas podem fazer-se representar, num mesmo período de tempo, em diferentes instâncias de direção.

Até o ano 2000, o CPERS/SINDICAT0 tinha 85.361 sócios, sendo que, destes, 75.920 são docentes (Tabela 1). Esses valores revelam uma taxa de filiação alta, embora seja difícil o oferecimento de dados precisos quanto à relação filiação/base da categoria, considerando-se, em primeiro lugar, que compreende tanto professores na ativa quanto aposentados. Para ter-se uma idéia (dados do mesmo ano), dos docentes filiados, 48\% (36.447) são aposentados e 52\% (39.473) estão na ativa (Tabela 11). Em segundo lugar, porque os números apresentados pela SEE-RS (Secretaria Estadual de Educação do Rio Grande do Sul), quanto ao pessoal docente do sistema público estadual de ensino, obedecem a critérios de coleta diferentes daqueles usados pelo CPERS, pois se referem a matrículas, ou seja, uma mesma pessoa pode ser contada duas vezes caso ocupe mais de um cargo (20h e $40 \mathrm{~h}$, por exemplo).

Tabela I: Total de sócios (até 11.04.2000)

\begin{tabular}{|l|r|r|}
\hline $\mathbf{N}^{\mathbf{0}}$ de docentes & 75.920 & $89 \%$ \\
\hline $\mathbf{N}^{\mathbf{0}}$ de funcionários & 9.441 & $11 \%$ \\
\hline Total & $\mathbf{8 5 . 3 6 1}$ & $\mathbf{1 0 0 \%}$ \\
\hline
\end{tabular}

Fonte: CPERS/SINDICATO - Depto de Processamento de Dados.

Tabela II: $n^{0}$ de sócios docentes aposentados ${ }^{*}$ versus $\mathrm{n}^{0}$ de sócios docentes na ativa (até 20.11.2000)

\begin{tabular}{|l|l|l|}
\hline $\mathbf{N}^{0}$ de docentes aposentados & 36.447 & $48 \%$ \\
\hline $\mathbf{N}^{0}$ de docentes na ativa & 39.473 & $52 \%$ \\
\hline Total & 75.920 & $100 \%$ \\
\hline
\end{tabular}

Fonte: CPERS/SINDICATO - Depto de Processamento de Dados.
De todas as formas, o que gostaria de enfatizar é a representatividade do CPERS, não apenas pelo seu número de filiados, mas porque se constitui em uma organização que tem conseguido mobilizar o professorado público estadual, no transcorrer de seis décadas, para lutas sociais mais amplas, bem como para negociar em favor do professorado, com o Estado, questões salariais e relativas à carreira. Ademais, tem incluído outros segmentos em suas bases, tendo em vista a unificação de forças. Se a inclusão desses - como, por exemplo, servidores de escola - apresenta uma função mais aritmética que ideológica ou se há consenso a respeito do acerto dessa decisão, essas são conclusões aparentemente pouco claras, como poderemos ver a seguir.

\section{Sindicalização e identidade: trabalhadores em Educação?}

0 objetivo desta seção é discorrer sobre as concepções apresentadas por militantes de um sindicato de trabalhadores em Educação em relação às conexões entre sindicalização e identidade docente. Trata-se, então, de verificar se as posições apresentadas aproximam-se de algumas hipóteses possíveis, por exemplo, a sindicalização como resposta a um processo de proletarização, ou seja, o reconhecimento de que o professorado estaria privado de parcelas de sua atividade profissional, com diminuição da autonomia suficiente para planejar e executar suas tarefas e a concomitante organização em entidades massivas. Assim, a questão central é investigar como os envolvidos na pesquisa, ao equacionar ou conceituar o que seja um trabaIhador em Educação, enquadram os membros do professorado.

Como vimos em páginas anteriores, alguns autores resenham a criação de entidades docentes aos moldes sindicais como resultado de um processo de identificação do professorado com demais setores explorados da sociedade. A consciência da exploração (capitalista) e da opressão (política) conduz a uma alternativa universalista de organização: os sindicatos. 
Não obstante, o mais significativo nas percepções colhidas junto a militantes do CPERS, no que tange ao tema objeto, é que existe uma multiplicidade de posições a respeito, mesmo entre o primeiro grupo investigado, composto por ativistas experientes e renomados. Isso é o que veremos a seguir.

\section{Primeiro grupo: dirigentes em nível estadual}

A priori, poder-se-ia esperar a existência de uma concepção subjacente às posições dos/as entrevistados/as, proveniente de programas da entidade e/ou de discussões travadas nas instâncias do movimento. Entretanto, sobre o que significa ser 'trabalhador em Educação', houve sim uma concordância, mas pela ausência de menção: nenhum dos oito sujeitos do primeiro grupo operou com a idéia de proletarização como perda de autonomia no processo de trabalho, definição apresentada por autores que trabalham o tema (Apple, 1987; Fernández Enguita, 1991). Isto é, eles e elas, ao desenvolverem idéias sobre o alegado fenômeno de proletarização do professorado, que os teriam aproximado dos demais trabalhadores, não se dirigiram à natureza do trabalho docente, à sua divisão, à multiplicação de tarefas etc. Ativeram-se mais a questões de caráter ideológico, bem como indicaram aspectos que são mais resultado de um processo de proletarização; conseqüência, não causa; assediados/as por preocupações principalmente sobre o salário e a necessidade de melhoria na carreira dos filiados.

Isso não significa, por outro lado, simples ignorância ou falta de análise quanto à situação do trabalho docente. Em primeiro lugar, porque os/as sindicalistas também são pessoas que partilham representações sobre suas ocupações e, considerando que apresentam distintos matizes político-ideológicos, é natural que suas interpretações sejam variadas e não necessariamente vinculadas a uma visão acadêmica do fenômeno. Em segundo lugar, porque as análises sobre a situação do trabalho docente devem ser realizadas tendo em mente as configurações históricas que o têm caracterizado, e isso cada um/a de nossos/as entrevistados/as faz, ou seja, insere sua interpretação resgatando a especificidade dos contextos vividos pela categoria.

Contudo, é relevante observar o quanto as divergências atingem o núcleo da questão 'profissional versus proletário', mas no âmbito das disputas ideológicas, misturando posição com identidade de classe. Examinemos, então, os argumentos utilizados pelos sujeitos.

Podemos agrupar os achados colhidos entre os oito entrevistados em duas categorias: os que afirmam que o professorado pode ser enquadrado como uma categoria de trabalhadores proletarizados e os que discordam disso.

Abordando em primeiro lugar os que defendem o enquadramento, há duas possibilidades. Primeiro, há quem não se contente com a dicotomia proletários versus profissionais, acrescentando "que as coisas são muito mais difíceis de definir do que esse simplismo, entre burguesia e proletariado", aparentemente associando o conceito de profissional ao de burguesia. Essa entrevistada define proletário como "aquele que é oriundo das classes mais baixas e que vende a sua força de trabalho por um salário", e por essa definição aí localiza os docentes. Aqui, a referência de análise usada é a da posição de classe (aliás, vários dos entrevistados fazem referência a esse aspecto). Por outro lado, de forma mais imprecisa, afirma que "[...] a nossa categoria é uma categoria profissional no momento em que ela procura trabalhar o melhor possivel dentro daquele campo que the compete".

Segundo, usando como referência a questão da identidade, existe quem argumente que o professorado se considera trabalhador porque isso corresponderia a "traços de esquerda" típicos da categoria, vinculados à idéia do seu trabalho intelectual: "[...] somos trabalhadores com um papel, com uma função, dentro da área intelectual, mas somos trabalhadores e essa identificação hoje existe na categoria”.

Os que discordam da identidade proletária utilizam argumentos preferencialmente de 
ordem cultural. Encontramos quem tenha ojeriza à idéia de que os docentes sejam considerados trabalhadores, alegando que essa tentativa de mudança de perfil não é correta (não corresponderia à realidade) nem foi assimilada pela categoria, ou seja, a categoria nunca teve e ainda não tem identidade com os trabalhadores. Diga-se de passagem que tal posição é um pouco estranha ao provir de uma dirigente sindical.

Por outro lado, há quem se refira à característica conservadora dos docentes para explicar a falta de desejo de chamarem-se dessa maneira. Uma variante desse argumento é apresentada por quem tenta compreender os motivos que conduzem os docentes a não se identificarem com os trabalhadores, incluindo a manipulação de subjetividades realizada pelos governos:

[...] vivência dicotômica de ser uma elite e ao mesmo tempo eu sou um trabalhador que às vezes ganha menos do que uma empregada doméstica [...]. Mas enquanto dizem que eu sou uma nobre professora faz bem pro meu ego, de uma certa forma resgata aquilo que me levou a optar por essa profissão, porque eu não vim só e muito menos por causa de salário, eu vim porque eu gostava desse trabalho, da educação [...].

\section{Segundo grupo: militantes de base}

Em se tratando do segundo grupo investigado, composto por pessoas com menor experiência política e mais tênue delimitação ideológica, a abordagem do tema foi feita de outra maneira: foi-lhes perguntado o motivo de sua participação pessoal nas atividades sindicais. A maioria absoluta indicou a organização da categoria na demanda por direitos, encaixando-se numa razão solidária para a participação, tal como podemos perceber por meio do escrito de uma das respondentes: “[...] a necessidade de união e organização da categoria para ter mais forças na reivindicação de tudo o que precisamos e temos direito".

Outras razões aduzidas apresentam caráter mais ideológico, tendo em vista a trans- formação social e, mesmo, a luta pela qualidade da educação como, por exemplo: "estar engajado na construção de um mundo melhor, repleto de felicidade e cidadania"; e "combater a exploração, a alienação e o entreguismo".

Há ainda razões de caráter instrumental: "toda a minha vida profissional tem sido acompanhada pelo sindicato. Atendida em todas as consultas feitas"; o que não deixa também de expressar certa gratidão e, por conseqüência, manter relação com um motivo de caráter solidário.

De todas as formas, não há que tomar tais afirmações como tipos-ideais que não se relacionam, haja vista que as mesmas pessoas defendem motivos de caráter diferenciado. A articulação entre motivos instrumentais e solidários é evidente, bem como se percebe que os comentários não abordam aspectos concernentes às mudanças na organização do trabalho docente e suas conseqüências sobre a atividade pedagógica propriamente dita.

\section{Terceiro grupo: direção intermediária}

Por fim, quanto ao terceiro grupo de sindicalistas entrevistados, é perceptível certa uniformidade em suas perspectivas sobre as possiveis articulações entre sindicalização e identidade, considerando, inclusive, que pertencem à mesma corrente sindical. 0 tema foi trabalhado com eles sob dois enfoques.

No primeiro deles, procurou-se acompanhar a aproximação das/os entrevistadas/os ao sindicato. Guardando-se as diferenças de gênero, que indicam trajetórias diversas conforme se trate dos homens ou das mulheres, há similitude no que tange a seu interesse e inserção nas atividades sindicais, ou seja, são apaixonados/as por sua experiência. As questões de caráter ideológico e solidário se articulam, sendo mais evidente, na narrativa das mulheres, um início de militância por motivos de caráter solidário, enquanto no caso masculino percebem-se com mais força motivos de ordem ideológica.

Já o segundo enfoque foi abordado por meio de uma questão mais direta a respei- 
to dos motivos pelos quais as pessoas em geral se sindicalizam ao CPERS.

Sobre esse último enfoque, há três principais temáticas a sublinhar. Uma delas é mais evidente, pois se refere ao convencimento dos referidos sujeitos sobre a importância da atividade sindical. Isso implica resgatar o papel do sindicato como agente que pretende melhorar a situação da categoria e a qualidade da educação: em síntese, trata-se de buscar a melhoria da sociedade. Todos os sujeitos foram veementes nisso, e alguns se esforçaram para deixar claro que, na condição de funcionários públicos, thes cabe prestar um bom serviço à população, e é por isso que também se organizam e reivindicam, embora essa convicção tenha sido adquirida na 'caminhada'. Esse tipo de perspectiva aproxima-se da idéia de um sujeito universal de classe, mas guarda relação com a imagem de funcionários de Estado indicada por Nóvoa.

Uma segunda temática diz respeito ao significado da auto-identificação como 'trabalhadores em Educação', inclusive a partir da incorporação do segmento de funcionários de escola ao sindicato. Mesmo que esse movimento de inclusão já esteja institucionalmente superado, posto que já faz mais de uma década que tenha ocorrido, não é perceptível homogeneidade nas alusões a respeito. Não encontramos, aqui, divergências de concepções como as presentes entre os sindicalistas do primeiro grupo, mas simplesmente ausência de consideração. Somente a funcionária e um dos docentes se referem mais diretamente ao título de 'trabalhadores em Educação'. Os demais membros do professorado não tocam no assunto, dirigindo-se mais à atividade docente e à especificidade do trabalho realizado, como as relações pedagógicas e o ensinar para a cidadania.

0 professor fala do assunto quando afirma a necessidade de evitar o corporativismo, para poder partilhar lutas e seguir avançando. Porém, em seus argumentos, deixa perceber que há desconforto e resistência na categoria quanto à identificação como trabalhadores em Educação:
Às vezes eu vejo alguém dizer assim: ah mas agora, imagina nós desfilando com os sem-terras lá em Porto Alegre, como fizemos vários desfiles e estavam os sem-terras juntos, ele são trabalhadores também. Outro diz assim: não essa história agora que o CPERS inventou que trabalhador em educação, nós somos professores, tudo bem nós somos professores mas quem é o professor, é um trabalhador, é um trabalhador não é, então o sindicato mostra que nós temos que às vezes e não poucas né, ter essa visão é, coletiva do trabalhador né, a luta é dos trabalhadores né, pode ser um trabalhador da área rural, trabalhador da área... da indústria, do comércio, é trabalhador que nem nós né que nem somos nós professores.

A única funcionária na diretoria é mais veemente, até porque utiliza grande parte de sua fala para esclarecer a situação de seu grupo dentro do sindicato e a relação que mantém com o Estado. Critica a falta de identificação do professorado com o termo trabalhadores em Educação, afirmando que há docentes, especialmente homens, que não admitem ser chamados assim:

\section{[...] um professor numa escola uma vez me disse} assim: mas como que vocês me chamam de trabalhador de educação, eu estudei tanto, me formei numa faculdade, como é que vou ser chamado de trabalhador?

E também se refere ao sentimento de exclusão de funcionárias quando organismos, tais como a imprensa, ignoram esse segmento quando tratam do CPERS/SINDICATO, confirmando o que acima foi dito sobre o desconforto da categoria quanto ao tema, embora, segundo ela, as direções e demais militantes do sindicato estejam convencidos do acerto da integração dos segmentos.

A última temática reflete uma certa desilusão quanto ao interesse apresentado pelo professorado em relação ao labor que o sindicato leva adiante. Os sujeitos tratam disso quando respondem aos motivos que levam os traba- 
Ihadores em Educação a sindicalizar-se, enfatizando os de caráter instrumental como os mais significativos, fator que é citado com pesar quando a motivação se reduz a isso, ou seja, ao desejo de obter vantagens mais imediatas, embora justas. Veja-se a manifestação que, abaixo, serve de exemplo:

Eu vou lá, eu vou me associar, eu pago aquele, aquela mensalidade taxinha irrisória mensalmente e tenho quem lute por mim, e esquece que é uma luta de categoria é uma coisa de classe, é uma coisa de união que quanto mais se soma a luta mais força se tem, as pessoas não têm essa visão, a maioria não tem essa visão.

A questão da participação, em um sentido amplo, também é indicada: as pessoas querem participar de "congressos", de "cursos", "querem sair um pouco, conhecer coisas novas". No entanto, somente uma professora apresenta três tipos de motivos - solidários, instrumentais e ideológicos:

As pessoas têm vários motivos, tem pessoas que acham assim, que até já me disseram que acham bonito o CPERS, que já fez aqueles movimentos que agora nem tem né, enormes, de encher o Gigantinho, de botar vinte mil pessoas, de fazer movimento na rua, então em seguida que eles vão, fazem concurso no Estado eles já procuram o sindicato pra ter a sua carteirinha do CPERS. Tem um outro professor que quer assim saber dos direitos, então ele só quer saber do umbigo dele, do que que ele tem direito né, e tem um outro professor que acredita na luta, que acredita que através de um sindicato a gente pode ter avanços né, e entra por idealismo mesmo né, pra melhorar a educação, pra melhorar as escolas, o salário e tudo né, pra uma série de coisas que se luta há tantos anos.

Finalmente, pode-se aferir, pela manifestação dos sujeitos, que ainda que percebam como poucas as pessoas que efetivamente partilham de sua perspectiva, chamada por uma informante de 'idealismo', não pretendem desistir de seu labor, como faz questão de destacar um docente:

[...] essa utopia que eu tenho, [...] essa vontade de construir um mundo melhor, mais humano, mais fraterno, que não tenha discriminação de gênero, de raça ou de religião, é um desafio que continua em pé [...].

\section{Idéias conclusivas}

0 principal propósito deste artigo foi problematizar alguns dos sentidos atribuídos à identidade dos docentes no que tange à autoconsideração como profissionais ou proletários. Os resultados, obtidos a partir da análise das percepções de membros de entidades sindicais de trabalhadores em Educação, parecem indicar que para essa polarização não há respostas únicas ou posicionamentos fechados. Como vimos, mesmo entre aqueles que atuam cotidianamente numa entidade concebida por semelhança com organizações de trabalhadores proletarizados, não há acordo. A dubiedade se percebe tanto na inserção do professorado em uma ou outra categoria - profissionais ou proletários -, quanto na escolha de critérios ou de argumentos para definir o tipo de identidade que se defende.

Antes de seguir, há que dizer que o termo identidade está sendo usado de maneira bastante ampla: são as características que conformam os seres humanos, mas que, como já foi citado, não são nem estáticas nem essenciais, sendo construídas e reconstruídas por estes no transcorrer de suas vidas. Assim, no que tange ao âmbito das representações a respeito do seu próprio trabalho, cada indivíduo e a sociedade qualificam o que significa ocupar determinado posto de trabalho, mesmo que de formas contraditórias ou diferenciadas. No meu entender, assumir essa perspectiva de análise permite que nos afastemos de uma concepção funcionalista de ocupação, que arrolaria as características de uma profissão como definitivas e a-históricas (Popkewitz, 1994). 
As imagens e auto-imagens sobre os mestres - parafraseando Arroyo (2002) - vêm sendo modificadas no transcorrer da história do ofício docente. A identidade proletária é uma dessas imagens, que expressa as contradições vividas pelo professorado no momento presente. Movimento contraditório porque, tendo em conta que este percebe a diminuição de seu campo de atividades, imprensado entre atribuições divididas - mas não compartilhadas -, multiplicação de tarefas-meio e redução salarial, resiste de duas formas diferentes: reivindica 'profissionalização' e fortalece organizações criadas por semelhança com entidades de trabalhadores manuais. Cabe chamar a atenção para o fato de que proletarização não é sinônimo de baixos salários - estes são conseqüência daquela. Proletarização é sinônimo de perda de autonomia no trabalho. Ora, aqui há uma situação paradoxal, porque a introdução de maior regulação no trabalho docente, ou seja, de proletarização, tem sido justificada como uma manifestação de processo de profissionalização técnica do mesmo, por parte das organizações (Estado, empregadores). Esse paradoxo apresenta-se como um desafio para a atuação das associações docentes: como desenvolver noções de profissionalidade e qualificação diferenciadas das noções institucionais?

Sobre isso, Valle argumenta que a busca da profissionalização, por parte do professorado,

[...] neutraliza - ou anula - a identidade negativa que associa a atividade de ensinar às tarefas domésticas. 0 magistério ganha status de profissão e deixa de ser visto como subprofissão, pseudoprofissão, semiprofissão, profissão secundária, complementar ou marginal. (2002, p. 215)

Porém, como acomodar esse desejo com a outra identificação anunciada, a de "trabalhadores em Educação'?

A atribuição desse conceito ao conjunto de pessoas que se ocupam da área educativa, em algumas redes/níveis de ensino, parece ser mais uma opção não compartilhada. Embora já esteja oficializado nos estatutos dos sindicatos 'docentes' - que, portanto, não são mais apenas docentes, ainda que mantenham o nome -, não é consenso entre o professorado nem ao menos dentro das próprias direções sindicais.

No Brasil, outra nuance desse processo foi a filiação dos referidos sindicatos à CUT que, em alguns casos, constituiu-se num resultado doloroso e extremamente disputado. Bulhões; Abreu (1992) narram o início dessa discórdia no CPERS/SINDICATO, que começa oficialmente com sua transformação em sindicato, em 1989, sendo que foi somente em 1996 a filiação da entidade à CUT.

No entanto, o problema pode ser ainda mais complexo. Os servidores compõem uma categoria bem menos numerosa e com menor poder de fato e de direito, visto que as tarefas que desenvolvem geralmente são caracterizadas pela ausência de relação institucional com o saber, principal objeto de trabalho dentro das escolas. $\mathrm{Na}$ verdade, é mais como se os funcionários fossem subsumidos na categoria dos docentes e não o inverso, como o nome 'trabalhadores em Educação' pareceria indicar. Ou seja, é a natureza do trabalho de ensinar que parece dar a tônica à identidade dos ‘trabalhadores em Educação' sindicalizados, aquilo que fazem os sujeitos cujas tarefas são mais complexas e, por isso, possuem maior influência na gestão educacional. Por esse motivo, acredito que pesquisar as relações entre docentes e servidores/as nas escolas se constitui num importante veio de análise.

Outro problema significativo, que deve continuar a ser investigado, refere-se à identidade ocupacional dos/as docentes, especialmente dos sujeitos mais jovens, recrutados mais recentemente para a ocupação. Vários trabalhos se referem à modificação das identidades docentes na contemporaneidade. Para Birgin; Duschatzky; Dussel (1998), algo do/a docente redentor/a se mantêm, mas se modifica a noção da vocação como central para a categoria, bem como é evidente que os atuais docentes possuem outro perfil sociocultural. Dubet; Martuccelli 
(1998) colaboram na compreensão do fenômeno diferenciando identificação de status e identificação de ofício. Aparentemente, o professorado sofre mais no que tange a seu status social, porque a construção social sobre o que compete à tarefa docente parece subsistir nos discursos a respeito.

Arroyo vai mais adiante e lança dois questionamentos que gostaria de abordar, por fim. Retomando o fio de suas análises em texto já citado aqui, ele parte da necessidade, apresentada pela categoria docente, de situarse numa 'cultura profissional', numa 'cultura identitária'. Para tanto, ele resenha a trajetória da categoria, explicitando a convivência de diferentes identidades. Vale a pena transcrever trechos de sua abordagem:

Desde final dos anos 70 tentam identificar-se perante a sociedade como trabalhadores em educação. Poderíamos ver nesse gesto apenas uma estratégia de luta por salários, carreira, estabilidade, até uma justificativa para usar as mesmas formas de luta aprendidas pelo movimento operário, as greves, protestos, manifestações de rua. Poderíamos ver, ainda, nessa identidade de trabalhadores a procura de reforço das centrais sindicais. Podemos ver mais. Um aspecto a destacar poderia ser a percepção dos docentes da necessidade de incorporar um reconhecimento social, uma identidade coletiva que sempre lhes foi negada. (2002, p. 190)
Não obstante, o autor não é condescendente ao se questionar sobre a identificação do professorado com as necessidades e os interesses dos estudantes e suas famílias:

Proclamar-se os professores como trabalhadores em educação tem significado ser incorporados nessa cultura do trabalho acumulado em tantas lutas da classe trabalhadora? Acrescentou novos traços à desfigurada imagem de mestre de escola? Eles e elas se reconhecem como trabalhadores(as) fora dos tempos de greve? Se identificaram mais com os valores e a herança cultural da classe trabalhadora? Se reconhecem trabalhadores ou para eles mesmos esse traço acrescido a sua imagem a tornou mais confusa? Será suficiente para afirmar uma nova cultura profissional? (Arroyo, 2002, p. 190)

Sua resposta parece ser "não necessariamente", e podemos aproveitar, entre outras, duas de suas reflexões para seguir adiante. Primeiro, se não seria importante pensar em uma identificação como trabalhadores mais pela luta por direitos e por ética e menos propriamente por um perfil operário. Segundo, se existe essa luta por determinadas convicções, seria adequado examinar se, contraditoriamente, não são reprodutoras muitas das práticas realizadas no cotidiano da sala de aula, quando refluem as atividades mobilizatórias, distanciando-se das concepções de mundo dos grupos que freqüentam a escola, especialmente a pública.

\section{Referências bibliográficas}

APPLE, M. Relações de classe e de gênero e modificações no processo do trabalho docente. Cadernos de Pesquisa, São Paulo, n. 60 , p. 3-14, fev. 1987

ARROYO, M. Ofício de mestre; imagens e auto-imagens. 6. ed. Petrópolis: Vozes, 2002.

Operários e educadores se identificam: que rumos tomará a educação brasileira? Educação \& Sociedade, São Paulo, n. 5 , p. 5-23, jan. 1980.

BIRGIN, A.; DUSCHATZKY, S.; DUSSEL, I. Las instituciones de formación docente frente a la reforma: estrategias y configuraciones de la identidad. Propuesta Educativa, Buenos Aires, n. 19, p. 24-35, dic. 1998 
BOURDIEU, P. Os três estados do capital cultural. In: NOGUEIRA, M. A.; CATANI, A. (Orgs.). Pierre Bourdieu: escritos de educação. 2. ed. Petrópolis: Vozes, 1999. p. 71-79.

BULHÕES, M. da G.; ABREU, M. A luta dos professores gaúchos (1979/1991): o difícil aprendizado da democracia. Porto Alegre: L\&PM, 1992.

CARDOSO, A. M. Sindicatos, trabalhadores e a coqueluche neoliberal: a era Vargas acabou? Rio de Janeiro: Fundação Getúlio Vargas, 1999.

CLAUSSE, A. A Idade Média. In: DEBESSE, M.; MIALARET, G. (Orgs.). Tratado das ciências pedagógicas. São Paulo: Ed. Nacional/ Ed. da USP, 1977. v. 2: História da pedagogia. p. 81-186.

CPERS/SINDICATO. Estatuto Social. Porto Alegre: CPERS/Sindicato, 1994.

DUBET, F.; MARTUCCELLI, D. En la escuela: sociología de la experiencia escolar. Buenos Aires: Losada, 1998.

FERNÁNDEZ ENGUITA, M. A ambigüidade da docência: entre o profissionalismo e a proletarização. Teoria \& Educação, Porto Alegre, n. 4, p. 41-61, 1991.

FERREIRA, M. 0. V. Representações sobre relações de gênero entre sindicalistas do CPERS/SINDICATO. In: REUNIÃO ANUAL DA ANPEd, 27., 2004, Caxambu. Anais... São Paulo: ANPEd, 2004. CD-ROM.

GADOTTI, M. Estado e sindicalismo docente: 20 anos de conflitos. Revista ADUSP, São Paulo, p. 14-20, dez. 1996.

GUERRERO SERÓN, A. ¿Por qué el profesorado no se sindica? In: SÁNCHEZ, J. M. (Ed.). La sociología de la educación en España. Madrid: J.M.S. Editor, 1991. p. 187-195.

LOURO, G. Mulheres na sala de aula. In: DEL PRIORE, M. (Org.). História das mulheres no Brasil. 5. ed. São Paulo: UNESP/ Contexto, 2001. p. 443-481.

NÓVOA, A. Para o estudo sócio-histórico da gênese e desenvolvimento da profissão docente. Teoria \& Educação, Porto Alegre, n. 4, p. 109-139, 1991.

PETITAT, A. A escola e a produção da sociedade. Educação \& Realidade, Porto Alegre, v. 14, n. 2, p. 21-30, jul./dez. 1989.

POPKEWITZ, T. S. (Comp.). Modelos de poder y regulación social en pedagogía: crítica comparada de las reformas contemporáneas de la formación del profesorado. Barcelona: Ediciones Pomares-Corredor, 1994.

SOUZA, A. N. de. Movimento sindical docente: a difícil trajetória. In: LEITE, M. de P. (Org.). 0 trabalho em movimento: reestruturação produtiva e sindicatos no Brasil. Campinas: Papirus, 1997. p. 113-174.

TIRAMONTI, G. Sindicalismo docente y reforma educativa en la América Latina de los '90. In: TIRAMONTI, G.; FILMUS, D. (Coord.). Sindicalismo docente \& reforma en América Latina. Buenos Aires: FLACSO/Temas, 2001. p. 111-146.

VIANNA, C. Os nós do "nós": crise e perspectivas da ação coletiva docente em São Paulo. São Paulo: Xamã, 1999.

YANNOULAS, S. Educar: ¿una profesión de mujeres? Buenos Aires: Kapelusz, 1996.

Recebido em 27.06.05

Aprovado em 17.04.06

Márcia Ondina Vieira Ferreira, professora da Faculdade de Educação da UFPel, é doutora em Sociologia pela Universidad de Salamanca (Espanha), com pós-doutorado na FLACSO/Argentina. Tem pesquisado e orientado investigações sobre trabalho docente e relações de gênero; educação, gênero e sexualidades; e desigualdades e diferenças culturais. 